\title{
Alcohol Dehydrogenase and Aldehyde Dehydrogenase Genotypes and Alcoholism among Taiwanese Aborigines
}

\author{
Wei J. Chen, E.W. Loh, Yun-Pung P. Hsu, and Andrew T.A. Cheng
}

\begin{abstract}
Previous population association studies have indicated that certain alleles of alcohol dehydrogenase $(A D H)$ and aldehyde dehydrogenase $(A L D H)$ genes may reduce the risk of alcoholism in Oriental populations. In this report we determined the genotypes for three genes, $\mathrm{ADH} 2, \mathrm{ADH} 3$, and $\mathrm{ALDH} 2$ among subjects with alcohol dependence $(\mathrm{n}=159)$ and ethnically matched normal controls $(\mathrm{n}=149)$ for the four largest aboriginal groups (Atayal, Ami, Bunun, and Paiwan) in Taiwan. The ethnicity matching used in this study was feasible because there are still few intergroup marriages between these aboriginal groups. On a group level, the rare frequencies of $\mathrm{ALDH} 2 * 2$, the inactive allele of $\mathrm{ALDH} 2$, among these aborigines may account partially for their vulnerability to alcohol use disorders. On an individual level, however, the genotypes controlling alcohol metabolism did not account for intragroup differences in vulnerability to alcoholism except in the case of $\mathrm{ADH} 2$ for the Ami ethnic group. (C) 1997 Society of Biological Psychiatry
\end{abstract}

Key Words: Alcohol dehydrogenase, aldehyde dehydrogenase, alcoholism, association study, genetic, aborigines

BIOL PsyChIATRY 1997;41:703-709

\section{Introduction}

Polymorphism in the three genes that encode for the principal enzymes involved in the metabolism of alcohol and its metabolites, i.e., $A D H 2, A D H 3$, and $A L D H 2$, may contribute to the widely observed individual and racial differences in patterns of alcohol consumption and reac-

\footnotetext{
From the Division of Epidemiology and Public Health, Institute of Biomedical Sciences, Academia Sinica, Taipei, Taiwan (EWL, YPPH, ATAC); and Institute of Epidemiology, College of Public Health. National Taiwan University, Taipei, Taiwan (WJC).

Address reprint requests to Dr. Andrew T.A. Cheng, Division of Epidemiology and Public Health, Institute of Biomedical Sciences, Academia Sinica, Taipei. Taiwan.

Received August 17, 1995; revised February 1, 1996.
}

tions to alcohol, and hence the development of alcohol use disorders (Bosron and $\mathrm{Li} 1986$ ). Subjects with $A L D H 2 * 2$, the inactive allele of $A L D H 2$ that is predominant among Orientals and rare among Caucasians (Goedde et al 1992), experience more intense reactions to alcohol than subjects without $A L D H 2 * 2$ (Harada et al 1981). Although $A D H 2 * 2$ or $A D H 3^{*} 1$ may not increase the transient acetaldehyde to a level sufficient to cause marked flushing, it may still possess certain prohibitive effects over drinking behavior (Thomasson et al 1991). Since the kinetic differences among $\mathrm{ADH} 2$ isozymes are much more striking than those among the $A D H 3$ isozymes (Smith 1986), differences arising from the $A D H 2$ alleles may play a larger role than $A D H 3$ in affecting the risk for alcoholism. 
The involvement of alcohol metabolism genes in the development of alcoholism is further supported by the studies that compared allelic frequency of these genes in alcoholics and controls. Several reports have indicated that a reduced risk of alcoholism is associated with $A L D H 2 * 2$ and $A D H 2 * 2$ (Thomasson et al 1991, 1994; Higuchi et al 1995; Maezawa et al 1995; Chen et al in press), and $A D H 3^{*} l$ (Thomasson et al 1991; Chen et al in press) among Asian populations. Nevertheless, an association has not been observed among Caucasian populations (Gilder et al 1993). Thus, the role of alcohol metabolism genes in the development of alcoholism in different populations warrants further investigation.

Taiwanese aborigines, who can be distinguished by extensive differences in physiognomy, language, and sociocultural institutions (Chai 1967), have experienced a sharp increase in the prevalence of alcoholism within the past four decades (Cheng and Chen 1995). An investigation of these aboriginal groups may provide an opportunity to further characterize possible interactions between alcohol metabolism genes and environmental factors in the development of alcoholism. In this study we compared the frequency of genotypes for three alcohol metabolism genes among subjects with alcohol dependence and ethnically matched normal controls in the four largest aboriginal groups in Taiwan.

\section{Methods}

\section{Subjects}

Subjects tested in this study were derived from two sources. The first source was the Taiwan Aboriginal Study Project (TASP) (Cheng and Hsu 1992). In the phase I survey (1986-1988), 993 subjects randomly selected from four aboriginal groups (Atayal, Ami, Bunun, and Paiwan) were interviewed by a psychiatrist (Cheng) with a semistructured clinical interview schedule covering lifetime history of alcoholism. The reliability and validity of the instrument has been reported to be satisfactory (Cheng and Chen 1995). A phase II follow-up study was conducted approximately 4 years later (1990-1992), aiming at the estimation of incidence and the elucidation of risk factors of alcoholism. The same clinical interview for alcoholism was conducted by Cheng and two well-trained research assistants and venous blood was drawn for laboratory tests and DNA extraction. On the basis of the information collected from phase I and II surveys, those who met the DSM-III-R (American Psychiatric Association 1987) criteria of alcohol dependence with withdrawal symptoms were selected as cases in this study. If there was discordance between the information collected from phases I and II on a subject's status of alcohol drinking during the period before phase I, the information judged to be more accurate by the psychiatrist who participated in the clinical interview at both phases was taken. The decision was based on a careful evaluation of all information available, including that provided by key informants. Consequently the diagnosis of 25 subjects were changed. The reasons for the discordance included: subjects' willingness to admit their alcohol drinking problems after being informed of the abnormal findings of our laboratory tests at phase II, new information provided by family members and significant others who were unavailable at phase I, and negative answers attributable to memory effect or denial at either phase. The controls were subjects who had no history of alcohol drinking problems (either never drank or only occasionally drank in low quantity) and were matched on the basis of ethnicity and sex to each case. Since the prevalence of alcoholism among the four aboriginal groups is very high and genotypes are not normally altered with time, older eligible subjects were preferred as the matched control to avoid misclassification in phenotype.

The second source consisted of subjects who were not among the list of TASP, but recruited from the same aboriginal communities as TASP. Potential cases were initially referred to us via local health workers. The same research protocols used in TASP surveys were administered by one of the research team, a psychiatrist or well-trained research assistant, to confirm diagnosis and obtain blood samples. Thus, the majority of cases were identified from the community and few of them had ever been treated for alcoholism in any clinical setting due to poor accessibility of medical services. The selection of controls followed the same rule as in the first source.

Any subjects born to an intergroup marriage were excluded. Related subjects were also omitted. The male and female ratios of cases recruited for each aboriginal group were as follows: 25 and 12 (Atayal), 24 and 3 (Ami), 45 and 14 (Bunun), and 32 and 4 (Paiwan), while the ratios of male and female controls included: 19 and 12 (Atayal), 20 and 3 (Ami), 45 and 14 (Bunun), and 32 and 4 (Paiwan). The mean age of cases for each group ranged from 38.3 to 47.0 for men and from 36.7 to 57.0 for women. In contrast, the mean age of controls was older than cases for each group, ranging from 54.9 to 59.4 for men and from 52.6 to 66.3 for women. In total, 159 cases and 149 controls were included in the study. Because the amplification of certain genomic DNA was not satisfactory, the number of subjects genotyped for the three genes in this study varies.

\section{Genotype Determination}

After informed consent was obtained, $30 \mathrm{~mL}$ of venous blood was drawn from each participant. Ten milliliters was 
used for the isolation of leukocyte DNA according to the protocol of Sambrook et al (1989) or with a commercial kit GENOMIX (Talent, Italy). All polymerase chain reactions (PCRs) were conducted in a GeneAmp PCR System 9600 .

GenotyPING OF $\boldsymbol{A D H 2}$. According to Xu et al (1988), primers HE45 (5'AATCTTTTCTGAATCTGAACAG3') and HE46 (5'GAAGGGGGGTCACCAGGTTGC 3 ') were used to amplify exon 3 of $A D H 2$ and the PCR products digested with Mae III. The products were electrophoresed on $4 \%$ Nusieve agarose gel. DNA containing $\beta 1$ did not have the Mae III site and showed a fragment of $95 \mathrm{bp}$, whereas DNA containing $\beta 2$ was cleaved by Mae III and revealed a fragment of $65 \mathrm{bp}$. The PCR was carried out with $100 \mathrm{ng}$ genomic DNA, IX buffer $(10 \mathrm{mmol} / \mathrm{L}$ Tris- $\mathrm{HCl}, \mathrm{pH} 8.8$ at $25^{\circ} \mathrm{C}, 50 \mathrm{mmol} / \mathrm{L} \mathrm{KCl}$, and $0.1 \%$ Triton X-100), $1.5 \mathrm{mmol} / \mathrm{L} \mathrm{MgCl}_{2}, 50 \mathrm{pmol}$ of each primer, $1.25 \mathrm{mmol} / \mathrm{L}$ deoxynucleotide triphosphates (dNTPs), and 2 units of Tag polymerase in $50 \mu \mathrm{L}$ reaction mixture. The PCR conditions consisted of 35 cycles of $95^{\circ} \mathrm{C}$ for $1 \mathrm{~min}, 50^{\circ} \mathrm{C}$ for $1 \mathrm{~min}$, and $62^{\circ} \mathrm{C}$ for $1 \mathrm{~min}$, with a final extension of $62^{\circ} \mathrm{C}$ for $5 \mathrm{~min}$.

GENOTYPING OF ADH3. Two primers (5'-GAATCTGTCCCCAAACTTGT-3' and 5'-CTTTCCAGAGCGAAGCAGGT-3') were chosen to amplify a fragment of 123 bp surrounding codon 349 at exon 8 of $A D H 3$ (Walzer et al 1993). For $A D H 3^{*} 1$ allele, the PCR product was cut by restriction enzyme Ssp I into two fragments of $69 \mathrm{bp}$ and $54 \mathrm{bp}$ under recommended incubation conditions. The three fragments were differentiated using $10 \%$ nondenaturing acrylamide gel. The PCR was carried out with 100 ng genomic DNA, $1 \mathrm{X}$ buffer, $1.5 \mathrm{mmol} / \mathrm{L} \mathrm{MgCl}_{2}, 10 \mathrm{pmol}$ of each primer, $0.25 \mathrm{mmol} / \mathrm{L}$ dNTPs and $0.8 \mathrm{U}$ of Tag polymerase in $20 \mu \mathrm{L}$ reaction mixture. The PCR conditions consisted of $30 \mathrm{cycles}$ of $94^{\circ} \mathrm{C}$ for $30 \mathrm{sec}, 52^{\circ} \mathrm{C}$ for $45 \mathrm{sec}$, and $72^{\circ} \mathrm{C}$ for $45 \mathrm{sec}$, with a final extension of $72^{\circ} \mathrm{C}$ for $6 \mathrm{~min}$.

Genotyping of $\boldsymbol{A L D H 2}$. The method developed by $\mathrm{Tu}$ and Israel (1993) was used to amplify a $176 \mathrm{bp}$ fragment on exon 12 and upstream of intron 12 of $A L D H 2$. Primer \#1 (5'-CAAATTACAGGGTCAACTGCTATG$\left.3^{\prime}\right)$ was the same as the DCW11 developed by Crabb et al (1989). Primer \#2 (5'-GCCGCGCCCGCCGCCCCGCGCCCCCCCGCCCGCCCCGCGCTCCACACTCACAGTTTTCAC-3) was modified from the DCW 10 of Crabb et al (1989) by attaching 41 bp of GC-clamp to its 5 '-end, which was complementary to the known sequences surrounding the junction of exon 12-intron 12 of the $A L D H 2$ gene. The gene fragment of normal allele (CTGAAG) can be cut into two fragments ( $133 \mathrm{bp}$ and $43 \mathrm{bp}$ ) by a new restriction enzyme (Eco57I), whereas the mutant allele (CTAAAG) cannot. The three types of fragments were differentiated using $2 \%$ agarose gel. PCR was carried out with $100 \mathrm{ng}$ genomic DNA, $1 \mathrm{X}$ buffer, $1.5 \mathrm{mmol} / \mathrm{L}$ $\mathrm{MgCl}_{2}, 5 \mathrm{pmol}$ of each primer, $0.25 \mathrm{mmol} / \mathrm{L}$ dNTPs, and $0.8 \mathrm{U}$ of Tag polymerase in $20 \mu \mathrm{L}$ reaction mixture. The PCR conditions consisted of 35 cycles of $95^{\circ} \mathrm{C}$ for $30 \mathrm{sec}$, $55^{\circ} \mathrm{C}$ for $50 \mathrm{sec}$, and $72^{\circ} \mathrm{C}$ for $50 \mathrm{sec}$, with a final extension of $72^{\circ} \mathrm{C}$ for $6 \mathrm{~min}$.

\section{Statistical Analysis}

The differences in allele or genotype frequencies between cases and controls were examined by Fisher's exact test, and the test of the Hardy-Weinberg disequilibrium was performed by $\chi^{2}$ analysis with Yates' continuity correction (Weir 1990). Frequencies of the haplotype of $A D H 2$ and $A D H 3$ were estimated by using Hill's (1974) iteration algorithm. All tests were two tailed. Preventive fraction, which expresses the proportion of the potential total load of the disease that is prevented by the protective allele of the alcohol metabolism genes, was computed as

$$
\left.\left\{f_{i} /\left(1-f_{c}\right) R R+f_{c}\right]\right\}(1-R R),
$$

where $f_{c}$ is the fraction of cases with the protective factor and $R R$ is the measure of relative risk (Miettinen 1974). We did not correct for multiple comparisons since the relationship between alcohol metabolism genes and alcoholism has been reported elsewhere (Rothman 1990).

\section{Results}

All the genotype frequencies of $A D H 2, A D H 3$, and $A L D H 2$ within each aboriginal group did not deviate from Hardy-Weinberg equilibrium. Since $A D H 2$ and $A D H 3$ are closely linked on chromosome 4 , we examined the degree of linkage disequilibrium between the two loci in the sample. The maximum likelihood estimate of linkage disequilibrium coefficient. $D^{*}$, between $A D H 2$ and $A D H 3$ was significantly different from zero for the Atayal $\left(D^{*}=\right.$ $\left..0174, \chi^{2}=6.3, p<.002\right)$ and the Bunun $\left(D^{*}=.0258, \chi^{2}\right.$ $=10.2, p<.001)$; however, we did not detect any linkage disequilibrium between $A D H 2$ and $A D H 3$ for the Ami and the Paiwan. This was most likely due to lack of power caused by the extreme frequency of $A D H 3 * 1$ in the two groups (Thompson et al 1988).

The allelic frequency of $A D H 2 * 2$ among Ami cases was significantly lower than that for Ami controls (Table 1). The preventive fraction of $A D H 2 * 2$ in alcohol dependence for Ami was $44 \%$. No association between $A D H 2$ and alcohol dependence was found for the remaining three groups. There was no significant association between 
Table 1. Genotype Distributions and Allele Frequencies of $A D H 2$ among Four Aboriginal Groups in Taiwan

\begin{tabular}{|c|c|c|c|c|c|c|c|}
\hline \multirow[b]{2}{*}{ Group and status $(n)$} & \multicolumn{4}{|c|}{ Genotypes, $n$ (frequency) } & \multicolumn{3}{|c|}{ Allele frequencies } \\
\hline & $A D H 2 * I / * I$ & $A D H 2 * 1 / 2$ & $A D H 2 * 2 * 2$ & $\operatorname{FET}(p)^{a}$ & $A D H 2 * 1$ & $A D H 2 * 2$ & FET $(p)$ \\
\hline \multicolumn{8}{|l|}{ Atayal } \\
\hline Normal control (31) & $0(.00)$ & $9(.29)$ & $22(.71)$ & & .15 & .85 & \\
\hline Alcohol dependence (35) & $0(.00)$ & $5(.14)$ & $30(.86)$ & $>.10$ & .07 & .93 & $>.10$ \\
\hline \multicolumn{8}{|l|}{ Ami } \\
\hline Normal control (22) & $2(.09)$ & $9(.41)$ & $11(.50)$ & & .30 & .70 & \\
\hline Alcohol dependence (23) & $8(.35)$ & $8(.35)$ & $7(.30)$ & $>.10$ & .52 & .48 & .03 \\
\hline \multicolumn{8}{|l|}{ Bunun } \\
\hline Normal control (59) & $0(.00)$ & $19(.32)$ & $40(.68)$ & & .16 & .84 & \\
\hline Alcohol dependence (59) & $1(.02)$ & $16(.27)$ & $42(.71)$ & $>.10$ & .15 & .85 & $>.10$ \\
\hline \multicolumn{8}{|l|}{ Paiwan } \\
\hline Normal control (35) & $0(.00)$ & $10(.29)$ & $25(.71)$ & & .14 & .86 & \\
\hline Alcohol dependence (36) & $0(.00)$ & $12(.33)$ & $24(.67)$ & $>.10$ & .17 & .83 & $>.10$ \\
\hline
\end{tabular}

" $p$ value of Fisher's exact test (two-tail).

alcohol dependence and $A D H 3$ (Table 2) or $A L D H 2$ (Table 3 ) in any of the four groups investigated.

Because some controls aged less than 50 years might become alcohol dependent in the future and hence bias the difference between cases and controls toward null, our analysis was extended to include the deletion of young controls; however, the results remained the same (data not shown). When only men were included in the analysis, the results were also similar (data not shown).

\section{Discussion}

In this study, controls were selected from the same community as cases and their ethnicity strictly matched. This was feasible because there are still few intergroup marriages between these aboriginal groups (Cheng and Hsu 1993). This would make the relationship between alcohol metabolizing genes and alcoholism confounded by population admixture less likely. A single previous study also selected controls and cases from the same community
(Thomasson et al 1994). Other studies either recruited controls from students, physicians, staff, and blood donors (Thomasson et al 1991; Gilder et al 1993; Higuchi et al 1995) or did not specify the method used in the recruitment of controls (Maezawa et al 1995).

The frequencies of $A L D H 2 * 2$ in the four Taiwanese aboriginal groups, using the data from controls, are similar to those of Caucasians rather than Han Chinese, but the frequencies of $A D H 2 * 2$ in the four groups are similar to those of Taiwanese Hans rather than Caucasians (Table 4). Presumably the Taiwanese Hans may have dual protective mechanisms because they have relatively high frequencies of both $A D H 2 * 2$ and $A L D H 2 * 2$, and the Taiwanese aborigines have one protective mechanism from $A D H 2 * 2$. In contrast, Caucasians may have minimal protection from $A D H_{2} * 2$ and $A L D H 2 * 2$ since the frequencies of the two alleles are extremely low; however, the prevalence of alcohol dependence among Taiwanese aborigines is higher than in Caucasians. For example, the prevalence of alcohol dependence for men and women together was $1.5 \%$ for

Table 2. Genotype Distributions and Allele Frequencies of $A D H 3$ among Four Aboriginal Groups in Taiwan

\begin{tabular}{|c|c|c|c|c|c|c|c|}
\hline \multirow[b]{2}{*}{ Group and status $(n)$} & \multicolumn{4}{|c|}{ Genotypes, $n$ (frequency) } & \multicolumn{3}{|c|}{ Allele frequencies } \\
\hline & $A D H 3^{*} I /^{*} I$ & $A D H 3 * 1 / 2$ & $A D H 3 * 2 * 2$ & $\operatorname{FET}(p)^{a}$ & $A D H 3^{*} 1$ & $A D H 3^{*} 2$ & FET $(p)$ \\
\hline \multicolumn{8}{|l|}{ Atayal } \\
\hline Normal control (31) & $28(.90)$ & $3(.10)$ & $0(.00)$ & & .95 & .05 & \\
\hline Alcohol dependence (36) & $36(1.0)$ & $0(.00)$ & $0(.00)$ & .09 & 1.00 & .00 & .10 \\
\hline \multicolumn{8}{|l|}{$\mathrm{Ami}$} \\
\hline Normal control (23) & $23(1.0)$ & $0(.00)$ & $0(.00)$ & & 1.00 & .00 & \\
\hline Alcohol dependence (23) & $22(.96)$ & $1(.04)$ & $0(.00)$ & $>.10$ & .98 & .02 & $>.10$ \\
\hline \multicolumn{8}{|l|}{ Bunun } \\
\hline Normal control (58) & $51 \quad(.88)$ & $7(.12)$ & $0(.00)$ & & .94 & .06 & \\
\hline Alcohol dependence (59) & $52(.88)$ & $7(.12)$ & $0(.00)$ & $>.10$ & .94 & .06 & $>.10$ \\
\hline \multicolumn{8}{|l|}{ Paiwan } \\
\hline Normal control (35) & $34(.97)$ & $1(.03)$ & $0(.00)$ & & .99 & .01 & \\
\hline Alcohol dependence (34) & $34(1.0)$ & $0(.00)$ & $0(.00)$ & $>.10$ & 1.00 & .00 & $>.10$ \\
\hline
\end{tabular}

\footnotetext{
" $p$ value of Fisher's exact test (two tail).
} 
Table 3. Genotype Distributions and Allele Frequencies of $A L D H 2$ among Four Aboriginal Groups in Taiwan

\begin{tabular}{|c|c|c|c|c|c|c|c|}
\hline \multirow[b]{2}{*}{ Group and status $(n)$} & \multicolumn{4}{|c|}{ Genotypes, $n$ (frequency) } & \multicolumn{3}{|c|}{ Allele frequencies } \\
\hline & $A L D H 2^{*} I / * 1$ & $A L D H 2 * 1 / * 2$ & $A L D H 2 * 2 / 2$ & FET $(p)^{a}$ & $A L D H 2 * 1$ & $A L D H 2 * 2$ & $\operatorname{FET}(p)$ \\
\hline \multicolumn{8}{|l|}{ Atayal } \\
\hline Normal control (31) & $29(.94)$ & $2(.06)$ & $0(.00)$ & & .97 & .03 & \\
\hline Alcohol dependence (35) & $35(1.0)$ & $0(.00)$ & $0(.00)$ & $>.10$ & 1.00 & .00 & $>.10$ \\
\hline \multicolumn{8}{|l|}{ Ami } \\
\hline Normal control (23) & $22(.96)$ & $\mathrm{l}(.04)$ & $0(.00)$ & & .98 & .02 & \\
\hline Alcohol dependence (22) & $20(.91)$ & $2(.09)$ & $0(.00)$ & $>.10$ & .95 & .05 & $>.10$ \\
\hline \multicolumn{8}{|l|}{ Bunun } \\
\hline Normal control (58) & $56 \quad(.97)$ & $2(.03)$ & $0(.00)$ & & .98 & .02 & \\
\hline Alcohol dependence (59) & $59(1.0)$ & $0(.00)$ & $0(.00)$ & $>.10$ & 1.00 & .00 & $>.10$ \\
\hline \multicolumn{8}{|l|}{ Paiwan } \\
\hline Normal control (33) & $30(.91)$ & $3(.09)$ & $0(.00)$ & & .95 & .05 & \\
\hline Alcohol dependence (30) & $30(1.0)$ & $0(.00)$ & $0(.00)$ & $>.10$ & 1.00 & .00 & $>.10$ \\
\hline
\end{tabular}

" $p$ value of Fisher's exact test (two tail).

Taiwanese Hans (Helzer et al 1990), 9.2-11.3\% for Caucasians (Helzer et al 1990), and $17.1-32.0 \%$ for Taiwanese aborigines (Cheng and Chen 1995). Thus, in group comparisons, $A L D H 2 * 2$ is more important in preventing one from becoming alcoholic than $A D H 2 * 2$.

Interestingly, the frequencies of both $A D H_{2} * 2$ and $A L D H 2 * 2$ of the Taiwanese aborigines are similar to that found among Malays. These results are consistent with the contention that Taiwanese aborigines are descended from Malayo-Polynesian stock. The low frequency of $A L D H 2 * 2$ is also consistent with previous reports that Taiwanese aborigines are less likely than Taiwanese Hans to experience a flushing response subsequent to alcohol consumption (Chen et al 1989).

A potential weakness of preceding group comparisons may arise from the fact that they do not reflect the real situation for each individual. Persons with alcoholism within a high-risk group are not necessarily those who carry the susceptible genotypes. This has been called "ecological fallacy" (Greenland and Robins 1994). Thus individual data are needed to clarify the relationship between alcohol metabolism genes and alcoholism.

We found that within each aboriginal group, alcoholic subjects and nonalcoholic subjects cannot be distinguished on the basis of $A L D H 2$ or $A D H 3$. Although the extremely low frequencies of $A L D H 2 * 2$ among the subjects of this study might render the power insufficient, the impact of $A L D H 2 * 2$ would be marginal. This would also be the case for the study by Gilder et al (1993), in which neither Caucasian alcoholic nor nonalcoholic subjects were found to carry $A L D H 2 * 2$. Thomasson et al (1994) reported that the Atayal alcoholics tended to have a significantly lower frequency of $A L D H 2 * 2$ on the basis of a one-tailed test. But the difference was small $(0.02$ vs. 0.05$)$ and the preventive fraction was only $3 \%$. In contrast, the alcohol dependents and normal controls of Ami in this study show different distribution of $A D H 2 * 2$, and the preventive fraction of $A D H 2 * 2$ is $44 \%$; however, such an association between $A D H_{2} * 2$ and alcohol dependence was not seen for the remaining three aboriginal groups.

These findings highlight the importance of interaction between alcohol metabolism genes and sociocultural factors in the development of alcoholism. Although the rare frequencies of $A L D H 2 * 2$ among Taiwanese aborigines may make them vulnerable to alcohol use disorders, the prevalence of alcoholism remained relatively low until four decades ago when they began to experience tremendous sociocultural changes. Forty years ago the lifetime

Table 4. Allele Frequencies of $A D H 2 * 2, A D H 3^{*} l$, and $A L D H 2 * 2$ among Four Aboriginal Groups in Taiwan and Other Populations

\begin{tabular}{|c|c|c|c|c|c|c|c|}
\hline \multirow[b]{2}{*}{ Allele } & \multicolumn{4}{|c|}{ Taiwanese aborigines $^{a}$} & \multirow[b]{2}{*}{ Han Chinese ${ }^{b}$} & \multirow[b]{2}{*}{ Malays" } & \multirow[b]{2}{*}{ Caucasians $^{d}$} \\
\hline & Atayal & Ami & Bunun & Paiwan & & & \\
\hline$A D H 2 * 2$ & .85 & .70 & .84 & .86 & .73 & .59 & .04 \\
\hline$A D H 3^{*} I$ & .95 & 1.00 & .94 & .99 & .95 & - & .54 \\
\hline$A L D H 2 * 2$ & .03 & .02 & .02 & .05 & .30 & .03 & .00 \\
\hline
\end{tabular}

${ }^{a}$ Nonalcoholic controls of this study.

"Nonalcoholic controls of Thomasson et al (1991).

'Unscreened subjects of Goedde et al (1992).

Nonalcoholic controls of Gilder et al (1993). 
prevalence of alcoholism among Taiwanese aborigines ranged from $0.11 \%$ to $0.16 \%$ (Rin and Lin 1962); however, in the phase I TASP survey (1986-1988) we found that the four aboriginal groups had alarmingly high prevalences of alcoholism, ranging from $44.5 \%$ (Ami) to $54.5 \%$ (Bunun) according to DSM-III-R criteria (Cheng and Chen 1995).

On the other hand, the protective effect of $A D H 2 * 2$ or $A L D H 2 * 2$ is not absolute. Some subjects carrying one allele of $A D H 2 * 2$ or $A L D H 2 * 2$ still become alcohol dependent. In our sample, two alcohol-dependent Ami (9\%) were found to have $A L D H 2 * 2$. About $12 \%$ (Thomasson et al 1991) to $17 \%$ (Chen et al in press) of alcoholic Taiwanese Hans also had $A L D H 2 * 2$. Wall et al (1993) have found that although some effects of acetaldehyde may be aversive, individuals may also find some aspects of alcohol flush reaction pleasurable. It is interesting to note that a secular trend of the decreasing "protective effect" of $A L D H 2 * 2$ against developing alcohol use disorders has been observed in Japan within the past 10 years (Higuchi et al 1994). The proportion of alcoholic patients who were heterozygous for $A L D H 2 * 2$ increased from $2.5 \%$ in 1979 to $13.0 \%$ in 1992 ; however, the protective effect of double alleles of $A L D H 2 * 2$ may be absolute, because all studies thus far have not found alcoholics homozygous for $A L D H 2 * 2$, and in people homozygous for $A L D H 2 * 2$ hepatic $A L D H 2$ activity is absent and metabolism of acetaldehyde is severely impaired (Enomoto et al 1991).

\section{References}

American Psychiatric Association (1987): Diagnostic and Statistical Manual of Mental Disorders, 3rd ed rev. Washington, DC: American Psychiatric Association.

Bosron WF, Li T-K (1986): Genetic polymorphism of human liver alcohol and aldehyde dehydrogenases, and their relationship to alcohol metabolism and alcoholism. Hepatology 6:502-510.

Chai CK (1967): Taiwan Aborigines: A Genetic Study of Tribal Variations. Cambridge, MA: Harvard University Press.

Chen C-C, Lin S-K, Lee C-T, Hwu H-G, Yeh E-K (1989): Racial differences in subjective responses to alcohol: Biomedical implications for alcoholism. Chin Psvchiatry 3(suppl 1):23-33.

Chen WJ, Loh EW, Hsu Y-P, Chen C-C. Yu J-M, Cheng ATA (in press): Alcohol-metabolizing genes and alcoholism among Taiwanese Hans: Independent effect of ADH2. ADH3 and ALDH2. $\mathrm{Br} J$ Psychiatry.

Cheng TA, Chen WJ (1995): Alcoholism among four aboriginal groups in Taiwan: High prevalences and their implications. Alcohol Clin Exp Res 19:81-91.

Cheng TA, Hsu M (1992): A community study of mental disorders among four aboriginal groups in Taiwan. Psychol Med 22:255-263.
The findings that alcohol metabolism genes only account in part for alcohol drinking disorders are consistent with results of previous twin studies. Heath et al (1991) found that the inheritance of frequency or quantity of alcohol consumption is determined both by an abstinence dimension and an independent frequency or quantity dimension. Genetic effects accounted for $66 \%$ of the variance in women and $42-75 \%$ in men for frequency of alcohol consumption, and $57 \%$ in women and $24-61 \%$ in men for quantity of alcohol consumption. Thus, environmental factors are equally as important as genetic factors in the determination of alcohol drinking behavior.

In conclusion, the low frequency of $A L D H 2 * 2$ among Taiwanese aborigines may partially account for their vulnerability to alcohol use disorders; however, except for $A D H 2$ in the Ami, alcohol metabolism genes did not account for intraethnic differences in vulnerability to alcoholism.

This work was supported by grants from the National Science Council, Taipei (NSC 75,76-0301-H002-28, NSC 78,79-0301-H002-40, NSC 83-0203-B001-102, NSC 84-2331-B001-046), and a grant from the Department of Health, Taiwan, ROC (DOH-80-03; DOH-81-111).

The authors would like to acknowledge the hard work and excellent performance of our research assistants Misses J.C. Chang, C.L. Cheng, and J.Y. Kao and local public health workers in the fieldwork. The authors would also like to thank Drs. K.S. Yan, T.K. Hsieh, and W.J. Chyuan for their help in referring alcoholic patients to us, and Dr. S.J. Yin for cross-validating our genotyping methods.

Cheng TA, Hsu M (1993): Sex differences in minor psychiatric morbidity among three aboriginal groups in Taiwan: The effects of lineage. Psychol Med 23:949-956.

Crabb DW, Edenberg HJ, Bosron WF, Li T-K (1989): Genotypes for aldehyde dehydrogenase deficiency and alcohol sensitivity. $J$ Clin Invest 83:314-316.

Enomoto N, Takase S, Yasuhara M, Takada A (1991): Acetaldehyde metabolism in different aldehyde dehydrogenase-2 genotypes. Alcohol Clin Exp Res 15:141-144.

Gilder FJ. Hodgkinson S, Murray RM (1993): ADH and ALDH genotype profiles in Caucasians with alcohol-related problems and controls. Addiction 88:383-388.

Goedde HW, Agarwal DP, Fritze G, et al (1992): Distribution of ADH 2 and ALDH2 genotypes in different populations. Hum Genet 88:344-346.

Greenland S, Robins J (1994): Ecologic studies: Biases, misconceptions, and counterexamples. Am J Epidemiol 139:747760.

Harada S. Agarwal DP, Goedde HW (1981): Aldehyde dehydrogenase deficiency as cause of flushing reaction to alcohol in Japanese. Lancet ii:982.

Heath AC. Meyer J. Jardine R, Martin NG (1991): The inheri- 
tance of alcohol consumption patterns in a general population twin sample: II. Determinants of consumption frequency and quantity consumed. J Stud Alcohol 52:425-433.

Helzer JE, Canino GJ, Yeh E-K, et al (1990): AlcoholismNorth America and Asia. A comparison of population surveys with the Diagnostic Interview Schedule. Arch Gen Psychiatry 47:313-319.

Higuchi S, Matsushita S, Imsxeki H, Kinoshita T, Takagi S, Kono H (1994): Aldehyde dehydrogenase genotypes in Japanese alcoholics. Lancet 343:741-742.

Higuchi S, Matsushita S, Murayama M, Takagi S, Hayashida M (1995): Alcohol and aldehyde dehydrogenase polymorphisms and the risk for alcoholism. Am J Psychiatry 152:1219-1221.

Hill WG (1974): Estimation of linkage disequilibrium in randomly mating populations. Heredity 33:229-239.

Maezawa Y, Yamauchi M, Toda G, Suzuki H, Sakurai S (1995): Alcohol-metabolizing enzyme polymorphisms and alcoholism in Japan. Alcohol Clin Exp Res 19:951-954.

Miettinen OS (1974): Proportion of disease caused or prevented by a given exposure, trait or intervention. Am $J$ Epidemiol 99:325-332.

Rin H, Lin T-Y (1962): Mental illness among Formosan aborigines as compared with the Chinese in Taiwan. J Ment Sci 108:134-146.

Rothman KJ (1990): No adjustments are needed for multiple comparisons. Epidemiology 1:43-46.

Sambrook J, Fritsch EF, Maniatis T (1989): Molecular Cloning: A Laboratory Manual, 2nd ed. Cold Spring Harbor, NY: Cold Spring Harbor Laboratory Press, pp E.3-E.4.
Smith M (1986): Genetics of human alcohol and aldehyde dehydrogenases. Adv Hum Genet 15:249-290.

Thomasson HR, Edenberg HJ, Crabb DW, et al (1991): Alcohol and aldehyde dehydrogenase genotypes and alcoholism in Chinese men. Am J Hum Genet 48:677-681.

Thomasson HR, Crabb DW, Edenberg HJ, et al (1994): Low frequency of the $\mathrm{ADH} 2 * 2$ allele among Atayal natives of Taiwan with alcohol use disorders. Alcohol Clin Exp Res 18:640-643.

Thompson EA, Deeb S, Walker D, Motulsky AG (1988): The detection of linkage disequilibrium between closely linked marker: RFLPs at the AI-CIII apolipoprotein genes. Am J Hum Genet 42:113-124.

Tu G-C, Israel Y (1993): A new approach for the rapid detection of common and atypical aldehyde dehydrogenase alleles. Eur J Clin Chem Clin Biochem 31:591-594.

Wall TL, Gallen CC, Ehlers CL (1993): Effects of alcohol on the EEG in Asian men with genetic variations of ALDH2. Biol Psychiatry 34:91-99.

Walzer C, Turler H, Balant L, et al (1993): Determination of human alcohol dehydrogenase and acetaldehyde dehydrogenase genotypes by single strand conformation polymorphism in discontinuous buffer electrophoresis. Electrophoresis 14: $566-569$.

Weir BS (1990): Genetic Data Analysis. Sunderland, MA: Sinauer, pp 75-76.

Xu Y, Carr L, Bosron WF, Li T-K, Edenberg HJ (1988): Genotyping of human alcohol dehydrogenases at the $\mathrm{ADH} 2$ and ADH3 loci following DNA sequence amplification. Genomics 2:209-214. 